\title{
Systematic review of Neotropical Lauxaniidae genera: Cephalella Malloch (Diptera, Schizophora)
}

\section{Vera Cristina Silva ${ }^{1}$}

\begin{abstract}
SUMMARY. Cephalella Malloch, 1926, a monotypic Neotropical Lauxaniidae genus, characterized by the presence of long antennae and a prominently convex face, is reviewed. The range of $C$. fumipennis is amplied.

KEY WORDS. Cephalella, Diptera, Lauxaniidae, Neotropical Region, systematic
\end{abstract}

The knowledge of the Neotropical Lauxaniidae is poorly developed. Many authors in a general way have pointed out the difficulty in tackle the lauxaniid systematics (MALLOCH 1926, 1929; STUCKENBERG 1971; SHEWELL 1986, among the modern authors). It is necessary to take into account the range of the family in the region, the wide variety of forms and the absence of a suprageneric classification of the Lauxaniidae. The descriptions of the new genera found during this study on the Neotropical Lauxaniidae began to be published in PAPP \& SILVA (1995).

A group of genera was choosen as an initial approach to the systematics of the family in the Neotropical region. The group studied has long antennae, that is, the length of the first flagellomere is at least six times its basal width, and is close related to Lauxania Latreille, 1804. STUCKENBERG (1971: 519) considered that some genera seem to form a natural group, defined, at least partially, by the kind of frons (and associated characters) of Lauxania. The most common characters are a smooth tegument; bare, bulbous face; long antennae and sparse mesonotals hairs. It is composed by eight genera, including Cephalella Malloch, which one is revised here.

This study was done examining the material from the collections following listed: The National Museum of Natural History (USNM), Washington, D.C. (curators Dr. A.L. Norrbom and Dr. G.F. Hevel); The Entomological Museum, Department of Zoology, Utah State University (EMUS), Logan (curator Dr. W.J. Hanson); The Natural History Museum (BMNH), London (curator Mr J. Chaney).

\section{Cephalella Malloch}

Cephalella Malloch, 1926: 5. Type species Cephalella fumipennis Malloch (mon.).

Diagnosis. Face convex, with prominent rounded areas in the laterals; labrum exposed and almost so high as the face above the antenna; ocelli small and very close, ocellar seta absent; orbital seta reclined; scape approximately with the same length of pedicel, first flagellomere very long and slender, arista short plumose. Intralar seta absent. Female with four spermathecae.

1) Departamento de Ciências Biológicas, Faculdade de Ciências e Letras de Assis, Universidade Estadual Paulista. Avenida Dom Antonio 2100, 19800-000 Assis, São Paulo, Brasil. 


\section{Cephalella fumipennis Malloch, 1926}

Figs 1-6

Cephalella fumipennis Malloch, 1926: 5. Type locality: Costa Rica, San Mateo, Higuito.

Distribution. Mexico to Costa Rica.

Redescription. Head (Figs 1,2) slender in the lower part; general color brownish yellow. Ocellar triangle dark brown, close to the vertex. Frons rectangular, longer than wide; shinning yellow, without dark spots; approximately flat in profile; anterior margin not protruding over the antenna. Face short, its height no more than half the length of the frons; laterally with shining black humps. Parafacialia narrow, white pruinose near the antenna. Gena narrow. Labro exposed, well developed, almost so high as the face, shining black; palp well developed, dark brown. Occiput concave. Antenna: scape approximately with the same length of the pedicel, both brownish yellow; first flagellomere longer and slender, blackish brown; arista thickened at the base, shorter than the flagellomere, pectinated, with short hairs. Chaetotaxy: orbital anterior seta almost the same length of the posterior one, both reclined; inner vertical seta $2 / 3$ of outer vertical, both strong; postocellar seta cruciated; ocellar seta absent.

Thorax. Slightly narrow, long; mesonotum arched anteriorly; anterior part, including postpronotum, proepisternum and proepimerum brownish yellow, all other parts brown with light white pruinosity; scutellum flat, triangular. Chaetotaxy: 1 postpronotal seta; 2 notopleural setae; dorsocentral setae arranged $0+3$, all setae near the scutellum, not well developed and decreasing in size anteriorly; $1+1$ supralar setae; 1 intralar seta; 1 postalar seta; 1 acrostichal seta; 5 rows of acrostichals hairs; 1 anepisternal seta; 1 katepisternal seta; anepimerum bare; 2 scutellar setae, short; 2 proepisternal setae.

Wing (Fig. 4) dark brown, paler posterior margin; r-m crossvein near the middle of the wing; $R_{4+5}$ and $M$ describing a curve near the apex. Halteres brown.

Legs (Fig. 3) brownish yellow, but apex of fore femur and hind tibia, base of fore tibia brown; first fore tarsomeres and last two mid and hind tarsomeres black. All tibiae with at least one pre-apical bristle; fore femur with postero-ventral row of bristles and some posterior bristles; mid femur with antero-apical row of bristles.

Abdomen dark brown, with white pruinosity; margins of the tergites with longer bristles. Female terminalia (Figs 5,7 ) short, tubiforme, dark brown; four spherical and smooth spermathecae (Fig. 6).

Material examined. Holotype female, Costa RicA, Higuito: San Mateo, Pablo Schild, type no. 28439 (USNM). MEXICO: San Luis Potosí, 6 mi S. Cd. Valles, 1 female (EMUS). BeLize: Toledo, 15 m n.w. of Punta Gorda, Big Fall., 3O-VIII1978, P.S. Broomfield leg., BM, 1979-33, secondary forest and scrub, 1 female (BMNH). Costa RicA: Ala $20 \mathrm{Km} \mathrm{S.} \mathrm{Upala,} 1$ female (EMUS).

Comments. The monotipic genus Cephalella was described by $\mathrm{MALOCH}$ (1926) to include the species C. fumipennis Malloch, 1926. This is a rare species in collections. Its distribution area was widened with this study. One female from 
Mexico, in a locality from the Neartic Region, was found in the EMUS collection. Unfortunately, no male specimen was found.
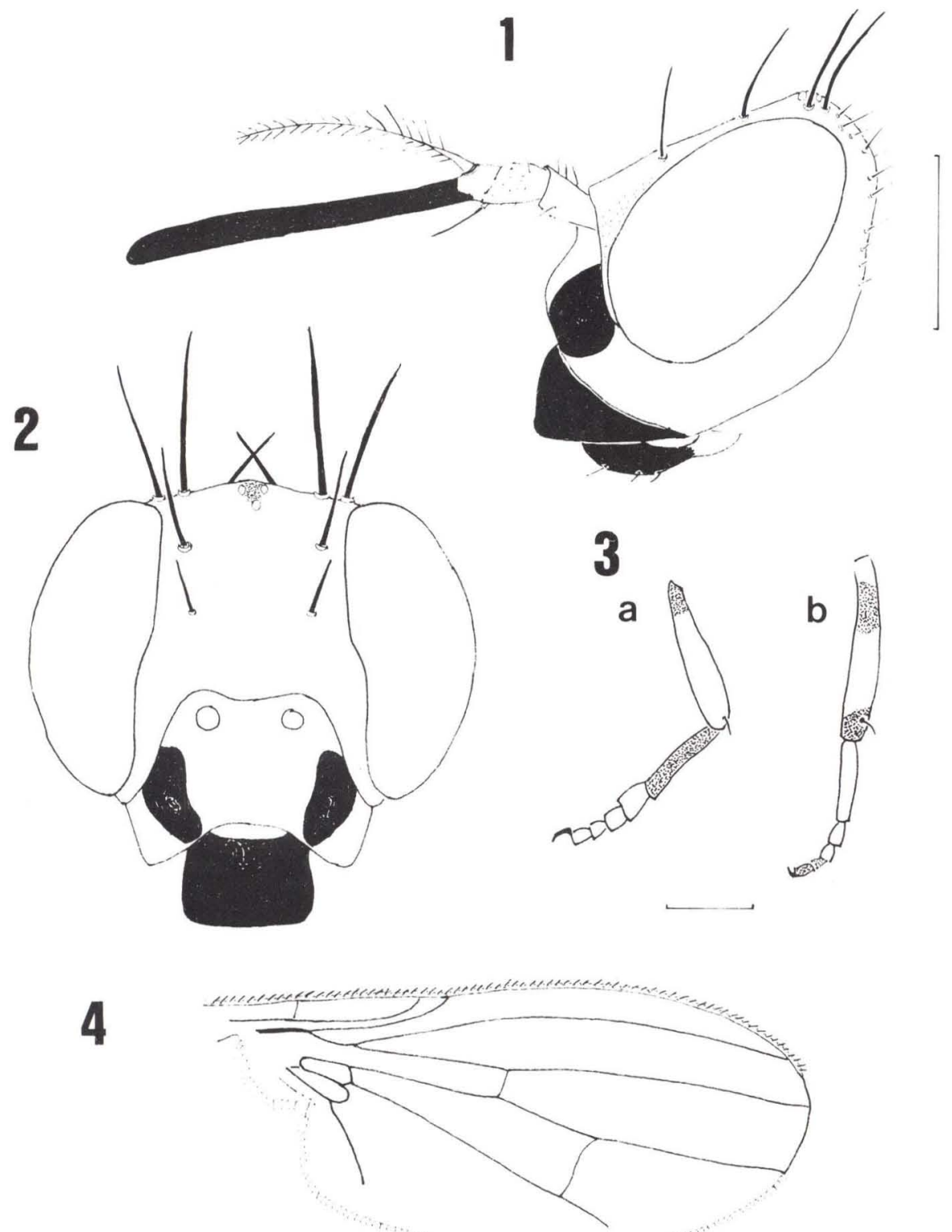

Fig 1-4. Cephalella fumipennis, Costa Rica, San Mateo, holotype. (1) Head, lateral view; (2) head, frontal view; (3) fore (a) and hind (b) right tibia and tarsi, anterior view; (4) right wing. Scales $0,5 \mathrm{~mm}$. 


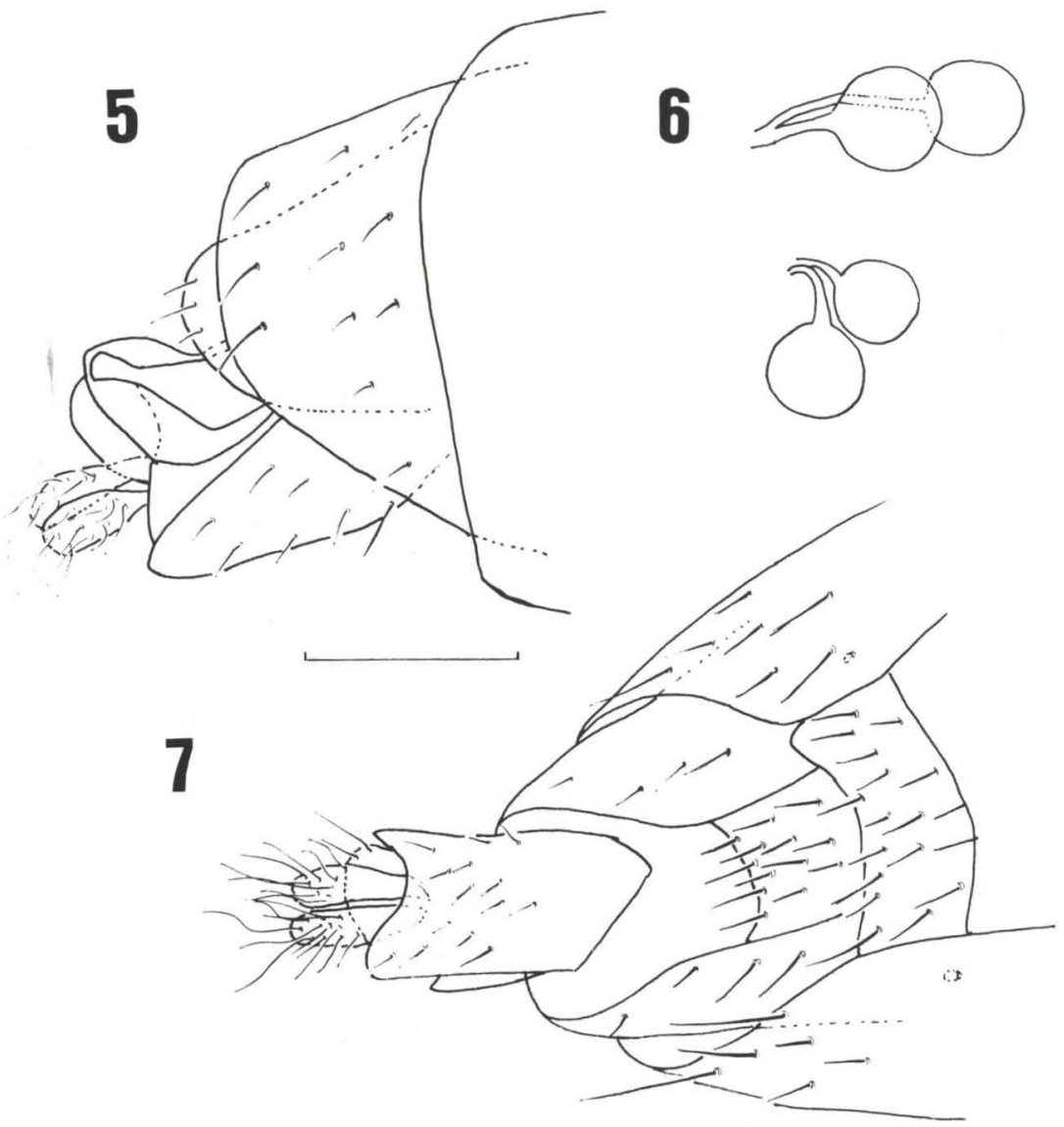

Figs 5-7. Cephalella fumipennis, Costa Rica, Ala (EMUS) female terminalia. (5) Lateral view; (6) spermathecae; (7) ventral view. Scales $0,2 \mathrm{~mm}$.

It was possible to study only the structure of the female terminalia. Three spermathecae, in Diptera, was considered by HENNIG (1958) as part of the basic plan of the Order. Therefore the founding of four spermathecae in the species studied is considered here an autapomorphie for the genus. MCALPINE (1981) indicated the presence of four spermathecae also in Chamaemyiidae. This last family is considered as part of the superfamily Lauxanioidea. In the point of view of GRIFFITHS (1972) and MCALPINE (1989) both families are in well-separated subgroups, and this character is considered as having arisen independently in both groups.

ACKNOWLEDGEMENTS. This study was done as part of a Ph.D. Thesis, developed at "Museu de Zoologia, Universidade de São Paulo" and presented at "Instituto de Biociências, Universidade de São Paulo". I am very grateful to Dr N. Papavero for the advice and 
encouragement. Dr. C.J.B. de Carvalho and Dr. C.C. Alberts helped with some sugestions. I want to thank the curators of the institutions who have borrowed the specimens for the study. Financial support was provided by CNPq, CAPES/PICD and FAPESP (Proc. Zool. 94/2031-8) grants.

\section{REFERENCES}

GRIFFITHS, G.C.D. 1972. The phylogenetic classification of Diptera Cyclorrhapha, with special reference to the structure of the male postabdome. The Hague, W. Junk, Series Entomologica, vol. 8, 340p.

HENNIG, W. 1958. Die Familien der Diptera Schizophora und ihre phylogenetischen Verwandtschaftsbeziehungen. Beitr. Ent. 8: 505-688.

MALlOCH, J.R. 1928. New genera and species of acalyptrate flies in the United States National Museum. Proc. U.S. Nat. Mus. 68 (21): 1-35.

. 1929. Exotic Muscaridae (Diptera). XXVI. Ann. Mag. nat. Hist. 4 (10): 97-120.

MCALPINE, J.F. 1981. Morphology and terminology - adults, p.9-63. In: J.F. McAlpine; B.V. Peterson; G.E. Shewell; H.J. Teskey; J.R. Vockroth \& D.M. Wood (Eds). Manual of Neartic Diptera. Ottawa, Biosystematics Research Centre, Monograph no. 27, vol. 1, 674p.

-1989. Phylogeny and Classification of the Muscomorpha, p. 1397-1518. In: J.F. MCALPINE \& D.M. WOOD (Eds). Manual of Neartic Diptera. Ottawa, Biosystematics Research Centre, Monograph no. 32, vol. 3, 248p.

PAPP, L. \& V.C. SilVA. 1995. Seven new genera of the Neotropical Lauxaniidae (Diptera). Acta zool. hung. 41 (3): 185-208.

SHEWELL, G.E. 1988. New American genera of Lauxaniidae, based on species of earlier authors, and a note on Lyciella rorida (Fallén) in North America (Diptera). Can. Ent. 118 (8): 537-547.

StUCKenBerG, B. 1971. A review of the Old World genera of Lauxaniidae (Diptera). Ann. Natal Mus. 20: 499-610. 